\title{
NOTAS SOBRE ALGUNAS REVISTAS LEONESAS DE ANTEGUERRA
}

\author{
por FRANCISCO MARTINEZ GARCIA
}

El panorama de la literatura leonesa de posguerra slele ser estudiado, por razones metodologicas, sobre la pauta que marcan los titulos de las revistas que aquí (en la ciudad de Iéón) nacieron, vivieron y murieron: Espadaña, Altano. Claraboja. Yeldo, Cuadernos Leoneses de Poesia, etc. El desconocimiento no siempre inocente-.- de nuestras cosas y la pretensión atizada por algunos de que nada válido se ha hecho en el pasado han llegado a crear una sólida corriente de opinión en el sentido de que la revista fue el gran invento de la cultura literaria leonesa de posguerra. Pero la verdad no es esa. Porque estas revistas, en realidad, se colocaron dentro de una corriente plenamente tradicional; es decir, que venia de atrás. El que se diera a esa corriente una forma, una fuerza y unos matices nuevos es una cuestión que no invalida la realidad fundamental.

En los años que van de 1900 a 1940 (el redondeo de las fechas es caprichoso) hay una bien nutrida tradición leonesa de revistas a las que, entre otros apellidos, se puede poner con loda validez el de aliterarias". Estas lineas no van a ser un estudio detenido de ninguna de ellas; ni siquiera una nómina de todas; van a ser unas "notas sobre algunaso de esas revistas. El objeto, además de informativo, es reivindicativo: probar sencillamente el hecho de la tradicionalidad y valorar el carácter y vigencia ininterrumpidos de la revista como medio cultural y literario en León: la prueba estara constituida por las revistas de anteguerra.

Los titulos que conviene retener son éstos; Literatura y' Arte, Juventud, Estudiante, El Guante Blanco, Lein y Vida Leonesa.

1. LITERAIURA Y ARTE fue fundada y dirigida por el sabio presbitero José Diez. Monar en 1907. Era el órgano de la Sociedad Leonesa de Excursiones. La prolongadísima vida de Dícz Monar .... falleció el 11 de diciembre de 1975 .... hace que la revista de referencia quede oculta en las nieblas del tiempo. Pero él mismo, en 1954, publicó la colección "Mis rimas" en ocho tomos; precede a los poemas del primero una "Nota preliminar a esta Colección" sobre "Poesia y Arte poético" que es una 
madura exposición de los principios estéticos que presidieron el intento literariocultural de Literatura y Arte.

2. JUvented estaba dirigida por Francisco Caballero Mier, un muchacho entonces allá por los años de la printera decada del siglo-. Colaboró con ét, entre otros, el celebrado escritor Mario Arnold (scudónimo de José Garcia). Juvenuad publico unos catorce numeros, lo que indica una notable pervivencia.

3. EstUDIANIr, con cinco o seis numeros de vida, fue realizada, como otras después, en la Imprenta Casado, en la que, por cierto, no se conserva ningún número, debido -...según me aseguró Mauro Casado a una inundación o algo por el estilo: todo el material de almacenes y archivos se echo a perder. En Estudiante colaboraron Francisco Pérez. Herrero hoy, sin discusión, por imperativos de la edad, el patriarca de las letras en nuestra ciudad y victoriano Cremer. Tal vez, el número más significativo de Estudiante fue un aextraordinario" dedicado a todos los meses del año: Pérez. Herrero hizo el mes de abril (primavera, Semana Santa. etcétera) y Crémer el de septiembre (otoño y sus connotaciones clásicamente literarias). Apareció Estudiante a finales de la decada de los años veinte: en 1929. Pérez. Herrero y Cremer estaban cntonees en el periodo de plena producción uen colaboración.

4. Lrón cra un semanario. El número 1 apareció el día 5 de enero de 1924 , siendo su director Manuel Torres Sampedro, su jefe de redacción José pinto Macstro (abogado muy prestigioso más tarde, periodista ágil y autor de la letra del himno a León compuesto por Odón Alonso) y su administrador José Luis Wagener. En el prólogo de este primer número queda fijada la posición exacta de la revista con estas palabras:

«Al margen de todo partido politico, sin dogal que la oprima ni marcado interes que la detenga, la revista león será portavoz de las justas aspiraciones del puteblo, recogiendo en sus columnas sus sinceros hatidos. Hablara de cuanto en beneficio de la región crea, y enarbolando única y exclusívamente la bandera de "por y para león", procurara que sus demandas, sean las que fueren, siendo justas, las escutehen desde lo mis alto,"

León pretende ser una voz libre e independiente de nitida impostacion leonesista. Sin embargo, la presencia en sus páginas de firmas que habian militado en revistas anteriores -en el mismo Guante Blanco hace que Léón deba ser colocada en el mismo "bando" conservador y medioburgués de las demás.

Dedicaba la página 3 a poesia. En esa página publicaron poemas: Eusebio Blasco, Pedro Mata, Nicolis Benavides, Alfredo Barthe, Félix Cuquerella, Antonio de Valbuena, Isaac Martín-Granizo, y muchos otros. Se publicaron también cuentos originales -y rigurosamente ineditos... para el concurso "León", patrocinado por la revista misma (1).

5. El Guante Blanco. El número I de El Guante Blanco. Semanario de Sociedad y Literario apareció a principios de 1918, tal vez el dia 6 de cnero,

(1) Leon, revista de la que aquí quedan expuestas unas mínimas señas de identidad, no tiene nada que ver con otra revista que empieza a publicarse en $1954 \mathrm{con}$ el mismo título en Madrid y que es la "Revista de la Casa de León” en la capital de España. Como tampoco tiene nada que ver con Vida Leonesa - que también consideraré inmediatamente-... la que. con el mismo título, en enero de 1958, empezará a publicar, con carácter mensual, Iuan Pastrana Garcia Ponce de León. 
domingo. En realidad, la fecha no figura en este primer numero, ni expresamente en la portada de ninguno de los demás números del primer año; pero en el número 2 (13 de enero). en el pie de imprenta que, de hecho, es el colofón-, se lee: "1918. Imp. Moderna de Alvarez, Chamorro Comp.. Cervantes, 3. León."

El Guante Blance no es una revista especificamente literaria. Es una revista de paladino talante clasista, burgues (semanario "de sociedad", se apellidaba) y casi, casi, una revista "del corazón». I o literario le viene por añadidura, pero hay que reconocer que esta añadidura es coherente y plenamente satisfactoria dentro de la línea adoptada. El "vaso de bon vino", que Berceo tenía como galardón suficiente a su mester poético, es canjeado aquí - - iy con qué placer! - por el aplauso de manos blancas, suaves y lindas; femeninas. El fundador y primer director "espiritual" de la revista fue José Egulagaray (al que hay que recordar como autor, muchos años más tarde, de dos libros leoneses de gran interes: Lo que va de ajer a hoy y La barca varada). Eguiagaray, en el numero 44, escribe aMi despedidan: es un corto articulo en el que recuerda los origenes de la revista y se ratifica en los objetivos primeros. Desde el I de noviembre (de 1918), Eguiagaray figura como "fundador". stendo el director Juan del Río Alonso.

Una de las cosas que más llama la atención es el uso de seudonimos: "Yo", "Kerensky", "Lluvia", "Sin Gracia", "Bartoldo", "Jacinto Rosa", "La Mano de Fatima", "El Censon, "Odegen, "Judex", "Cyrano de Bergerac", etc. La revista está hecha con la tecrica de una especie de rompecabezas en clave, de manera que bastantes de esos seudónimos tienen su solución (el nombre auténtico del colaborador) en la revista misma: basta leerla con detenimiento; este detalle la configura en su carácter, plenamente burgués, de juego de salón y de divertimiento.

La revista es un semanario que pretende tener informados a sus lectores de todo lo digno de nota que ha ido ocurriendo a lo largo de la semana en el ámbito leones en stis diversos aspectos: político, cultural, ecos de sociedad, deportes, etc., y dedicando una sección a otros ambientes pequeño-burgueses de la provincia: Astorga, Valencia de Don Juan. Benavides, La Bañeza, etc. Todo, y siempre, dentro de la linéa sutil. levemente irónica, casi frivola, tomada como propia en el número 1.

Las colaboraciones literarias son muy abundantes, mas en verso que en prosa. Una de las más interesantes es la sección "Siluetas de posse". mestra plenisimamente indicativa del caracter de rompecabezas, de acertijo o adivinanza, de pasatiempo, que la revista tenia. Las "Siluetas" eran dos poemas simetricos: el primero trazaba un retrato de mujer y el segundo un retrato de hombre. Los lectores, pertenecientes a una clase social reducida en la que todos se conocian, adivinaban con facilidad a quiénes se referian los versos de las "Siluetas" y reian despreocupadamente, al tiempo que los personajes aludidos - «ella" y uél»-- gozaban o rabiaban a tenor de lo favorecidos que la "silueta" los hubiera presentado.

Dejando aparte otros muchos detalles, subrayo el hecho de que a lo largo de bastantes números hubo una sección titulada "Poetas leoneses", en la que se daba la semblanza de un poeta en activo y se reproducía un poema original. Ni que decir tiene que la tendencia ideológica de los poetas escogidos estaba en total consonancia con la de la revista.

6. VIDA LEONESA. Vida Leonesa: Revista semanal ilustrada, nació en 1923, al tiempo que se fundaba ta "Sociedad Cultural y Deportiva Leonesa" de la que iba a ser, en principio, órgano oficial, como puede leerse en la cabecera del número 54 (6 de enero de 1924) que dice textualmente: "Vida Leonesa. Organo de la Sociedad 
Culural y" Deportiva. Director: Juliain Sanz Martinez. Administrador: Octavio Diez G. Canseco,"

Pero la revista no se redujo a lo que el stubtitulo puede stgerir. es decir, a ser una revista meramente deportiva: ni mucho menos: los "Deportes" eran una sección más. la última por cierto, de la revista.

Su presentación era espléndida en calidad de papel, tipos de imprenta, fotografias... Estas calidades, unidas a la altura intelectual. eran sólo la lógica consecuencia del cumplimiento de-dos objetivos que la revista misma se habia marcado y cuyo fuego se encargaba, de vez en cuando, de mantener encendido.

En el número 71 (12 de octubre de 1924) se convierte en quincenal y es su director Francisco Roa de la Vega. En el 74 se da un cambio fundamental: M. Morán del Val, que habia sido redactor jefe, pasa a director y propietario, con lo que empieza una "Nueva etapa". tal como se dice en el editorial, pero se cree innecesario marcar un programa nuevo porque se quiere que Vida Leonesa continue en la ideología de antes: se cambia de empresa y dirección, pero no de opinión.

El matiz reduccionista provinciano en ningún momento es de tono menor. Muy al contrario, se puede pensar en una muy inteligente operación por medio de la cual, la revista, ante la cantidad y urgencia de los problemas leoneses y ante la inoperancia de los lejanos poderes centrales, pretendió una cruzada de mentalización a nivel local (y provincial) justamente sobre los problemas locales (y provinciales) de todo tipo que desde aqui se veían con más claridad que desde el centro, e intentó, en consecuencía, despertar el aletargado ánimo de los leoneses inyectándoles fuertes dosis de realismo optimista para que. recuperada la confianza en sí mismos, se dieran cuenta de los problemas de león y de que podian ser solucionados por los propios leoneses; mas; que unicamente tendrian solución si los solucionaban los lconeses. y que éstos eran capaces de hacerio.

El leonesismo serio y consciente es, pues, una nota muy destacada de la revista: precisamente por esto se llamaba Vida Leonesa. En este sentido, en sus editoriales va dando ánimos y estimulos para la acción, hace balance de las cosas que se han hecho. rechaza comentarios contrarios a la línea seguida por la revista, ve de modo certero que el porvenir debe ser mirado con entusiasmo porque la juventud busca cultura, signo éste de vida, no de muerte.

En resumen: Vida Leonesa, que es, a mi juicio, la revista de más altura de los cuarenta primeros años del siglo $\mathrm{x} \times$ leonés, puede ser entendida asi:

a) Es una revista a la que se puede calificar, con toda justicia, como "culturaln. La cultura propugnada por ella es una cultura medularmente leonesista, hasta el punto de estar uno tentado de pensar que se dio un intento de crear una cultura leonesa autónoma, con valor en sí misma y sin la precisión de aperturas a lo que en el resto de España se estaba haciendo en el campo cultural.

b) La vida cultural modelo es para Vida Leonesa la de la propia ciudad; la popular no es considerada eficazmente, aunque se diga que si. Pero es lógico que esto ocurriera asi porque en el contexto burgués urbano, los problemas no ciudadanos ("populares") eran mirados con ojos casi exclusivamente folklóricos; por ello, aunque el folklorismo sea serio y consciente, queda convertido en material o instrumento cultural para uso casi exclusivo de la clase en ocio que es la que puede disfrutar de él. Por otra parte, si bien se hacen referencias a la cultura popular, estas referencias no han perdido el aroma ilustrado de un paternalismo benefactor; es 
Lecir, se quiere que el pucblo reciba la cultura burguesa, que venga a ella, no que el pueblo mismo sea el protagonisia y creador de su propia cultura. la popular ésta seria, de por fuerza, distinta a la cultura burguesa.

c) Es lógico, por todo ello, que Vida leonesa no sea una revista critica. Et talante critico iria inflexiblemente en contra del "status" y de su asentada $y$ confortable ideología, riesgo al que no se intentó llegar o que se evitó cuidadosamente. Seria exacto decir que de los grandes movimientos literarios contemporaneos (Modernismo, Vanguardias, etc.) se tenia en su redacción un conocimiento superficial y filtrado de ideología conservadora. por lo cual eran tenidos como malos, como atentadores contra la tradición literaria que tenia su fundamento en la distinción entre fondo y forma, díndose en todo caso la preferencia al fondo sobre la forma. No podian estar de acuerdo, por ejemplo. con el Modernismo, los clérigos conservadores glte exprimian sus sentimientos e ideas por medio del verso (que ellos llamaban "poesían). El mismo Roa de la Vega fue un detractor consciente, ya en sus años mozos, del Modernismo. A pesar de ello, la mayoría de los poetas que eseriben en Vida Leonesa no puede escapar en lo superficial a la influencia modernista. Por supuesto, nada hay en esta revista (ni en ninguna de las otras de las que he dado sucinta información) que tenga que ver, ni de lejos, con las Vanguardias que, por aquellos años. estaban en plena efervescencia. Esta automarginación. por ignorancia o por desprecio ideológico, puede tener su explicación en el mismo leonismo medular al que he aludido en primer lugar.

d) Pero nada de esto es impedimento para que deba ser reconocida a lida leomesa una calidad muy aceptable. La razón estriba en que la calidad intelectual. cientifica, histórica y literaria le viene dada por la categoria indudable de muchos de los escritores que en ella colaboraron.

\section{CONCLUSIÓN}

La mirada que hemos echado sobre las revistas leonesas de 1900 a 1940 es, a todas luces, fugaz y superficial. No puede ser de otra manera aquí. Con ello quedan sin estudio, pero no pueden quedar sin mención. Isis (1910). Anales del Instituto de León (1918-1920), Nuevo Rumbo (ya en 1937) y otras que se hacian en centros privados de enseñanza: tal, Ecos de mi Colegio (Colegio San Jose de los Hermanos Maristas), en la que, en 1938, publicó el jovencisimo Eugenio Garcia de Nora su primer poema: "Los caballitos."

Es suficiente lo dicho si queda clara la idea que al comienzo de esta efimera mirada formulé: no hace falta esperar a la posguerra para encontrar revistas literarias en León. Las hubo muchos años antes. Por esta razón, objetiva e históricamente demostrada, las revistas de posguerra deben ser consideradas dentro de esta tradición antecedente, respecto a la cual adquieren su motivo fundamental de ser y su peculiar individualidad. 